\title{
El campo otaku en Mexicali. Aproximaciones a la constitución de espacios y procesos de consumo urbano de la industria cultural japonesa Otaku field in Mexicali. Approaches to spaces constitution and consumption urban processes of Japanese cultural industries
}

\author{
Mario Javier Bogarín Quintana $a^{1,2}$ \\ Vinculación
}

Primera versión recibida en: 04 abril, 2017

Última versión recibida en: 19 junio, 2017

\section{Resumen}

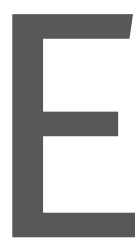

I propósito de este artículo es ofrecer una introducción, como observador participante, al campo del otaku mexicalense en los distintos espacios donde desarrolla su afición a través de distintas actividades que se relacionan con el mundo del manga y el anime. Es necesario acudir a estas zo-

1 Universidad Autónoma de Baja California. mariobogarin@uabc.edu.mx

$2 \quad$ Nacido el 30 de abril de 1983 en Mexicali, Baja California. Doctor en Ciencias Sociales (El Colegio de Michoacán). Profesor-Investigador Titular de Tiempo Completo en la Facultad de Artes de la Universidad Autónoma de Baja California. Es autor de los libros Saberes de la imaginación (2012), Interdisciplina y transformación simbólica del arte (2012), Elogio de lo inacabado (2013) y Estéticas liminales contemporáneas (2015) así como de dos docenas de publicaciones arbitradas. nas para practicar una etnografía que permita recopilar información que explique las características básicas de la predilección por esta forma de entretenimiento, como se plantea en el marco referencial. Esta será la vía, junto con los estudios de caso subsiguientes, para obtener un panorama global de las condiciones de este grupo en la localidad, lo que incluye sus acciones y procesos vitales para constituirse en grupo sociocultural.

Palabras clave: 1. Espacio; 2. Otaku; 3. Manga y anime; 4. Relaciones urbanas; 5. Arte pop.

\section{Abstract}

The purpose of this article is to offer an introduction, as a participant observer, to the field of otaku Mexicalense in the different spaces where it develops its hobby through different activities that relate to the world of manga and anime.

It is necessary to go to these areas to practice an ethnography to gath-

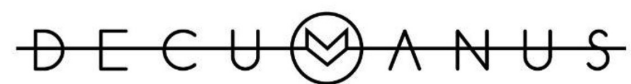

REVISTA INTERDISCIPLINARIA SOBRE ESTUDIOS URBANOS 
er information that explains the basic characteristics of the predilection for this form of entertainment, as it is raised in the frame of reference.

This will be the way, along with the subsequent case studies, to obtain a global picture of the conditions of this group in the locality, which includes their actions and vital processes to become a sociocultural group.

Keywords: 1. Space; 2. Otaku; 3. Manga and anime; 4. Urban relationships; 5. Pop art.

\section{Sumario}

- Introducción

- El gesto

- La convención - El ambiente elemental

- El cosplay

- La estructura de ambiente en el escenario

- La dinámica en el espacio

- Los jugadores

- Asociación de los otakus

- Otakus fans

- Las personificaciones

- La apariencia del otaku en sus espacios

- El otaku en la dinámica de los foros web

- Conclusión

- Referencias

\section{Introducción}

El presente documento se apoya en un marco teórico-metodológico y dos capítulos de investigación de campo. Estos se han desarrollado para confrontar la información ofrecida por los postulados originales de la historia del fenómeno a estudiar y de los conceptos generales basados en el marco teórico-referencial.

La búsqueda de los elementos característicos del campo otaku en Mexicali pasa por la interpretación de estos como signos de actividad entre iguales. La descripción de sus dinámicas tiende a materializar sus gustos e intereses en espacios concretos como pueden ser una convención, un foro de Internet o una reunión ocasional.

Respecto a la identificación de señales en un espacio como el mencionado, Clifford Geertz (1992: 4) establece que la cultura es un complejo de urdimbres de significación que busca interpretación.

El análisis consiste, pues, en desentrañar las estructuras de significación [...] y en determinar el campo social y su alcance. [...] etnografía es descripción densa. Lo que en realidad encara el etnógrafo [...] es una multiplicidad de estructuras conceptuales complejas, muchas de las cuales están superpuestas o enlazadas entre sí, estructuras que son al mismo tiempo extrañas, irregulares, no explícitas, y a las cuales el etnógrafo debe ingeniarse de alguna manera, para captarlas primero y para explicarlas después (Geertz, 1992:8).

La pertinencia del enfoque de Geertz radica en la concepción del proceso sociocultural que me ocupa como un campo de significación. La necesidad, a su vez, de presentar al proceso sociocultural como espacio de interpretación es la de interpretar desde un modelo local un fenómeno

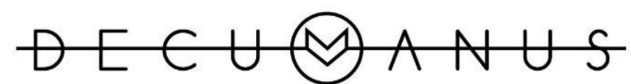

REVISTA INTERDISCIPLINARIA SOBRE ESTUDIOS URBANOS 
global. El propósito actual es describir espacios de prácticas, así como de referencias vivenciales relacionadas con el manga/anime.

Geertz (1992: 10) considera la importancia de conversar con los integrantes del grupo. Las formulaciones sobre sus sistemas simbólicos se extraen así desde la experiencia y las expresiones de sus miembros, y de ahí la importancia de un acercamiento a los gustos y gestos de un grupo en particular.

El objetivo que la descripción etnográfica densa persigue es el que fluye del discurso social. Busca que se construyan imaginarios, gustos y deseos a través de su planteamiento por el discurso del informante.

Cuando se aborda el tema de la interpretación, Geertz reconoce al escrito antropológico como una ficción (1992:14). Una interpretación de segundo o tercer grado es la "significación" desde la dimensión del autor.

Retomando una de las premisas de la descripción densa, las interpretaciones que haré no son por sí mismas inefectivas. Su valor consiste en su inserción dentro de las preguntas particulares, pero lo más importante, en la información que ofrecen del espacio en donde se observan los signos del grupo.

Lo importante, según Geertz, es lo dicho en el relato, el contenido de los deseos, las visiones y los gustos; la enunciación de la composición general del grupo, si bien se busca a partir de la especificidad de las necesidades a cubrir aquí, se hace mediante perspectivas microscópicas de cuestiones que, en apariencia irrelevantes, activan las conductas y procesos que

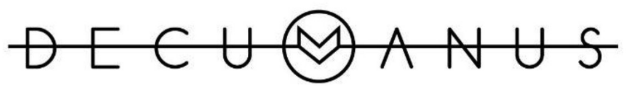

REVISTA INTERDISCIPLINARIA SOBRE ESTUDIOS URBANOS crean un estilo, las características del ser otaku.

Las convenciones de manga/anime son recientes en Mexicali. Gracias a las iniciativas promovidas por el grupo Anime Mexicali (animemexicali.net) se han podido organizar convenciones semestrales desde hace dos años y una serie de cuatro eventos anuales enfocados al cosplay.

La utilización de un recinto gubernamental como el Centro Estatal de las Artes en Mexicali da cuenta de la inserción de esta clase de eventos en el ambiente cultural bajo la consideración, por parte de las autoridades, de exposiciones de productos y obras de arte aficionado, en su mayoría dibujos (o fanart), pero también puestas en escena (cosplay).

La dificultad inicial de Anime Mexicali para verificar sus eventos en ese espacio consistió en la falta de convencimiento por parte del Instituto de Cultura de Baja California, administrador del Centro Estatal de las Artes (Ceart), de que se tratase de actividades más culturales que comerciales. Pronto, el grupo organizador convino en que dichas actividades debían presentarse como espacios de expresión de una comunidad que vivía cotidianamente cercana a productos artísticos de calidad comprobada por su abundancia en la actual cultura pop.

A partir de entonces, dentro del grupo y ante los responsables culturales, se ha establecido la línea central del apoyo a un grupo al que se le reconoce el potencial de poder expresarse en formas creativas a partir del manga/anime. Jamás, ni Anime Mexicali ni el ICBC, han considerado a la comunidad otaku mexicalense como un grupo 
"contracultural" ni integrado por individuos marginales.

Desde el principio, Anime Mexicali utilizó el slogan La cultura de la imaginación. El cultivo de una parcela cultural por parte de un grupo organizado sería suficiente para abrir las puertas de un espacio para la cultura legítima del estado. Ante la falta de identificación de los otakus por parte de la mayoría de la sociedad mexicalense, está claro el poco interés por preguntarse si se trata de un grupo contracultural o no, ni mucho menos peligroso.

Las dinámicas que se narrarán e interpretarán en este texto son, por una parte, las convenciones como espacios abiertos de identificación, pero también de vacío. Por otra, están los foros web donde los fanáticos del manga/anime pueden hablar sobre sus imaginerías en sus mismos términos con otros colegas.

La convención como estructura de ambiente a un nivel macro tiene la finalidad de reproducir los ámbitos de las convenciones extranjeras (japonesas, en particular) que, en tanto consagradas como lugares de reunión de grupos similares, están imbuidas de esa aura de validez que otorga el "ser japonés", esa condición que los otakus extraen de un ambiente repleto de productos japoneses que son los objetos de sus afectos.

Dicha puesta en escena, como las autoridades la entienden, consiste en la repetición de las diversas conductas y acontecimientos por los que la convención se identifica: venta e intercambio de manga/anime, proyección de anime, exposición de fanart, concurso y exhibición de cosplay, concurso de canto en japonés, venta de esclavos (una especie de subasta de acompañantes que deben compartir su visita a la convención con la persona que los "compró") presidida por el maestro de ceremonias que es el director de Anime Mexicali y conferencias a cargo de invitados especiales, que por lo general son actores de doblaje venidos desde la Ciudad de México.

\section{El gesto}

Aunque se creyera privativo de la escenificación del cosplayer (el fanático que se viste como un personaje de manga y anime), el acto de ensayar incluso ante el espejo, como lo dice una informante a modo de confesión, los rostros y gestos de distintos personajes ayudan a representar estados de ánimo: chicos y chicas se sonrien y cierran los ojos y, en el mejor de los casos, alzarán un brazo para descansar la mano en la nuca, para expresar embarazo.

Chicas, pero también muchos varones, entornan los ojos deseando hacerlos más grandes, tanto y tan brillantes como los de los personajes de anime en los que se pueden leer diversos sentimientos humanos que se pueden reflejar incluso en la mirada acuosa que ellos evocan con gran concentración y seriedad o, según el gesto, con un candor que quieren hacerlo sentir "suplicante", tal y como lo lucen los personajes sometidos a una gran tensión dramática o romántica. Expresan este sentimiento con coquetería y sin ella, aunque sea solo para apuntalar con frecuencia la credibilidad de sus disfraces y vestimenta.

Por supuesto, los otakus no están usando estas expresiones todo el

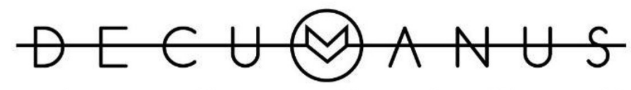

REVISTA INTERDISCIPLINARIA SOBRE ESTUDIOS URBANOS 
tiempo, y sus gesticulaciones, sobre todo en los puntos álgidos de la convención de fanáticos, pueden ser tan ordinarias o vulgares como las que más, con la diferencia básica de la dirección que estas toman.

Se trata de la dedicatoria a sus pares que se manifiesta en eventuales chillidos, uvés de la victoria con ambas manos acompañadas de sonrisas enmarcadas por los párpados apretados. Entonces basta con echar una mirada a los pósters que cuelgan detrás de nuestro(a) otaku, en uno de los puestos de venta, para muy seguramente encontrar la imagen de un personaje que ofrece un aspecto físico al que el convencionista de carne y hueso desea acercarse en gesto, fisico y vestuario.

Así, en la actuación alcanzada por formas distintas a exhibir, el fan otaku ya es su personaje, y caminando entre ellos se pueden encontrar variaciones de los gestos originales de los seres ficticios de las series y el cómic encarnados en los asistentes a la convención, cuyo aspecto y disfraces hechizos no siempre son fieles a la idea original: una Sailor Moon o un Ryu (Street Fighter II) que no parecen "copias fieles" a su original.

Se trata una galería de personajes que, o son demasiado sencillos para representarlos con mínima fortuna, o se pierden en los elementos como el traje genérico de guerrero ninja o samurái, por poner un ejemplo, que se apoya en la gestualidad de los movimientos de artes marciales reales o ficticias que además se presentan fundadas en gritos y expresiones que serían incomprensibles si no proviniesen del contexto del anime para com- prenderlas en su codificación a través del disfraz o de la preferencia por un determinado manga/anime.

Dicho lo anterior, se puede observar en el campo otaku que se ha vuelto constante la presencia de niños, incluso desde los tres años de edad, para cerrar el rango entre los siete y los ocho, que gritan a todo pulmón “¡kame-kame-ha!" (Goku, en Dragon Ball Z), y repiten distintas frases con la misma entonación con que lo hacen sus mayores.

Esto se observa con frecuencia y agudeza al recordar las opiniones que otakus al azar manifiestan al rememorar, muchas veces con prisa, sus inicios en este mundo de fantasías, y los gritos y movimientos bruscos se han generalizado en eventos donde hacen demostraciones de este tipo como parte de los concursos de cosplay. Ello como muestra de que dichas actuaciones como reproducciones de múltiples gestos no quedan limitadas a la relación entre pares, sino que se puede comprobar en minucias tales como los emoticonos (rostros formados por diversos signos ortográficos y lingüísticos que expresan sentimientos en conversaciones y mensajes electrónicos) que muchos otakus adoptan para su escritura.

\section{La convención - El ambiente elemental}

La integración de los otakus mexicalenses en grupos fue un reflejo de la necesidad de organizarse, tal como demostraban los otakus de San Diego y Los Ángeles, y pasaron varios años para que se llevaran a cabo las primeras convenciones en Mexicali: eventos

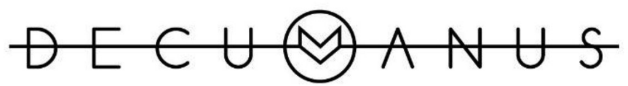

REVISTA INTERDISCIPLINARIA SOBRE ESTUDIOS URBANOS 
desorganizados e improvisados alrededor de mesas llenas de videocasetes y discos que contienen temporadas completas de anime y películas con actores reales (live action).

Podría afirmarse que el desarrollo del cosplay inició junto con estos primeros eventos, y los primeros comités organizadores surgirían de las peñas que se juntaban en los tianguis (Independencia, Mexicali Tianguis) y las primeras tiendas (III Mundo, Neurona), que como espacios de reunión sellarían la primera imagen "contracultural" de los otakus locales.

La dinámica básica de la convención hasta el momento funciona alrededor de dos fenómenos: se efectúan eventos en el Centro Estatal de las Artes cada semestre y ellos son fenómenos nuevos donde los informantes provienen de la tradición de los primeros otakus de principios de los noventa (que hoy tienen entre 25 y 35 años o más). Estos coinciden en ubicarse como centros donde hay una exhibición constante de personajes con vestuarios a veces hechos a mano; chicas que, como mínimo, desempolvan sus blusas y faldas escolares para interpretar a las colegialas japonesas que se repiten a lo largo de dos o tres géneros de manga/anime.

Los códigos que se leen en sus accesorios y gestualidades dependen del argumento en el que se inserten, ya sean Is, Azumanga daioh, Marshmallow boy o, desde luego, Sailor moon o Escaflowne. También es común encontrarse a un guardia imperial de Star wars, de los que abundan dos o tres tropas marchando armadas por los salones de la convención devenida escenario donde el asistente es tam- bién un actor para la imagen general del espacio.

Asistimos a la repetición de un ambiente como el que los otakus observan en las convenciones de San Diego o acaso Tijuana y como el que pueden conocer vía electrónica. Esto, con el objeto de aprender lo que es una convención japonesa, aunque, insisten los informantes organizadores, lograr una estructura de ambiente parecida en Mexicali fue algo que se logró hace tan solo tres o cuatro años.

La convención, como desde su inicio tianguero, se estructura alrededor de las mesas, las cuales lucen copadas de copias de temporadas completas en DVD de anime, pero también de películas. Cada temporada incluye todos los capítulos de anime que se emitieron durante un periodo de ocho a diez meses, a diferencia del ova (Original Video Animation), que son capítulos especiales que no forman parte de la trama principal y que son grabados para el consumo inmediato a través de VHS O DVD. Un DVD por treinta o cuarenta pesos; tres por cien pesos, y muchos otakus que no se atreven a pisar un tianguis con la asiduidad requerida descubren el espacio a rebosar de material nuevo (pero no desconocido) como una zona para establecer la red personal de la que la afición se alimenta.

La mesa es entonces la excusa para acercarse al vendedor, que informa sus datos generales y formas de localización electrónica y, con frecuencia, asegura una informante de nivel educativo medio superior, por el módico precio de uno, dos o los DVD vírgenes que sean necesarios, pueden hacerse de nuevas adquisiciones para su co-

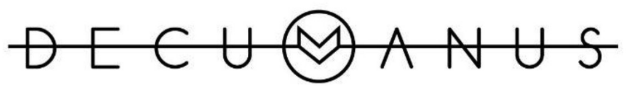

REVISTA INTERDISCIPLINARIA SOBRE ESTUDIOS URBANOS
Núm. 2. Vol. 2. Octubre 2016-Octubre 2017. Instituto de Arquitectura, Diseño y Arte.

Universidad Autónoma de Ciudad Juárez. ISSN: 2448-900X 
lección y queda claro, cuantas más preguntas se hacen, que el material expuesto es mínimo frente a la cantidad que se puede conseguir gracias a la buena disposición de los vendedores, otakus como los participantes.

\section{El cosplay}

Mientras tanto, los cosplayers se apropian del personaje a través de su exposición. Muchos participantes coinciden en que son "apropiados" por el usuario, más allá de cualquier fidelidad con algún personaje reconocible: las chicas con uniforme escolar no requieren mayor explicación, pero la jovencita con uniforme de capitana de nave espacial, cargando una llave gigante hecha de cartón y cubierta por medias de encaje; el individuo de grandes dimensiones vestido de negro, con la cara pintada cual mimo y una cubeta familiar de Kentucky Fried Chicken a manera de sombrero; o los otros jóvenes con camisetas de Megadeth, cargando un Pikachu (Pokemon) de peluche y tocados con orejas de conejo, ya son invitaciones a preguntar por la constitución del personaje.

Los paseos de cada personaje encarnado en los asistentes alrededor de la convención son giras panorámicas para su presentación en el escenario donde se muestran y se entienden a sí mismos como parte del atractivo plástico de los eventos, y es que existe el acuerdo de que "para que parezca" convención tiene que haber color, y esta noción de lo estético pasa por las pelucas, las faldas, las uñas, la pintura, los estampados, las capas, el disfraz entero como la clave argumental de su puesta en escena.
Entonces, una distorsión en el escenario de la convención, una nota discordante capaz de movilizar a la masa: a media tarde, tres chicas japonesas han entrado al salón, el uniforme escolar corto de verano y el gesto lánguido alternando con sonrisas chillonas y gritos exclamatorios, conduciéndose con paso negligente por los puestos de venta, y durante las horas restantes se oyen comentarios sobre su presencia y se descubren opiniones sobre lo evidente que es por ejemplo que una importante cantidad de los mil quinientos a dos mil asistentes acuden solo para ver el cosplay.

Algo similar puede percibirse en eventos como el Geek Fest, celebrado en el Ceart, donde un pianista chino interpretó al teclado numerosas piezas de videojuegos legendarios como Chrono trigger, Castlevania o el clásico Super Mario Bros., y el público no podía dejar de mirarlo. "Es que son especiales"; "Los japoneses lograron en décadas lo que nosotros no hemos podido en siglos"; o "¿Sabías que los asiáticos tienen una región especial en el cerebro que les permite entender su música tradicional?" Son expresiones que los ponen en la sintonía de apreciaciones confirmadas por las opiniones de sus asistentes, no solo varones, que no podian quitar los ojos de la colegiala japonesa, actitud respecto a la cual se había quejado una tal "Akemi" en el foro local animemexicali. net: "Los japoneses no somos monos de circo", siguiendo el hilo abierto en torno al tema de la "magia" de la raza amarilla por la que el otaku suspira alimentando el atractivo de la presencia en la convención de émulos de la colegiala Gogo Yubari (Kill Bill), quien

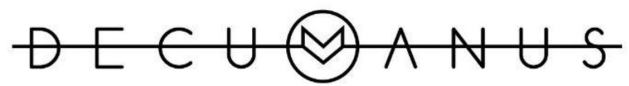

REVISTA INTERDISCIPLINARIA SOBRE ESTUDIOS URBANOS 
para muchos asistentes es la verdadera heroína de la película.

\section{La estructura de ambiente en el escenario}

Esto se vuelve un espectáculo que se aprecia como en un mercado de carne, pero mucho más colorido y multirreferencial. Hay una tensión sexual que se conecta con la propia del manga/ anime, al menos en las apreciaciones de las fantasías otakus que se asocian parcialmente a la imagen del consumidor que no tiene mucha vida social. "Yo casi no salgo, pero vengo aquí a comprar y a ver qué hay". Esta condición es conocida por los otakus que entienden las implicaciones de este apelativo: "Pero yo no soy otaku, ¿eh?”.

Hay un silencio general en el pequeño grupo de asistentes, muchos de ellos portando un mismo atuendo cosplay cuando, entre la algarabía de la comunidad, llega un sujeto con camiseta negra y zapatos lustrados que grita: "¿Es cierto que ustedes son perdedores?".

Los otakus no hablan mucho de sí mismos, pero se vuelve inevitable leer sus accesorios: "I love yaoi", y se esperaría por lo tanto ver a su portadora más adelante en una situación que, en la intimidad del grupo, delataría una tendencia homosexual como corresponde al género yaoi, que narra historias de temática gay, pero con el transcurso de las horas se observa que eso no pasa.

Se tiene que entender entonces el pastiche colorido de la convención; hay que recurrir a las historias detrás $y$, en el caso del campo, considerar la conducta antes descrita: los chicos y chicas con orejitas de conejo se pasean y se buscan para leerse el gusto por cada género y, en lo particular, la historia de manga/anime con sus argumentos predilectos, el gran flujo de sentidos comunes que unifican a todos los grupos de fanáticos (lo sean de los videojuegos o historias románticas o pornográficas) en la convención.

En el proceso de comercialización de la convención es constante la venta de comida japonesa. Es un elemento del ambiente, una clave de la apropiación $\mathrm{y}$, a decir de los informantes vistiendo cosplay, lo único que podrían comer como parte de la representación en el momento, y ellos quisieran en el momento contar con un tatami (alfombrilla tradicional) y un hibachi (hornillo) para almorzar ahí mismo, como en una actuación, y aun cuando reconocen la necesidad de conservar su propia personalidad, los gestos y el aspecto general responden constantemente, cuando les pregunto, a los guiños y signos faciales y movimientos que deben ser consecuentes con el personaje que desarrollan mientras comen.

\section{La dinámica en el espacio}

Las mitologías que cada otaku se construye sobre Japón son, para muchos informantes, los ingredientes centrales de los primeros impulsos por conocer al país; la profundización en su historia y sociedad marca la diferencia. Un trozo de sushi deja de ser alimento para ser recargado con los significados de los gustos personales muchas veces extraídos del argumento.

"Como comían en Evangelion". "Así se me afiguraba que sabía el arroz

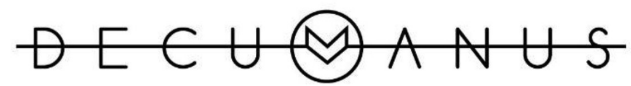

REVISTA INTERDISCIPLINARIA SOBRE ESTUDIOS URBANOS 
blanco en el restaurante de la Champú (Ranma 1/2)". Todo lo relacionado con una conducta aceptable para los miembros queda asignado a través de una comparativa entre escenas de los diferentes animes que es un alarde de conocimiento, condición para ser el personaje que se representa.

Las reglas sistemáticas en el otaku y su comunidad quedan así condicionadas a conductas acordadas: los participantes saben que una opción atractiva de mostrarse como tales es el concurso de canto de canciones en japonés (J-Pop), que nunca están correcta o incorrectamente interpretadas, sino que aparecen como un abanico del gusto específico del convencionista.

Desde temprano se empiezan a instalar las tarimas y el equipo de sonido para que los espontáneos se presenten a cantar y los aplausos y ovaciones y carcajadas le acompañen ya mediada la pieza y sus conocimientos fonéticos del japonés les granjean la complicidad de la asamblea: por lo general, no conocerán el idioma y dificilmente van más allá del puñado de vocablos integrados a sus vidas cotidianas, pero eso no importa. Su esfuerzo por cantar la canción se recompensa al identificarse como reconocimiento y a veces código de entrada al grupo. Por eso, cuando un asistente sube a interpretar Hey, Jude (The Beatles), decide no terminarla anticipando las rechiflas seguidas inmediatamente de aplausos comprensivos.

En este tenor, los otakus saben que no pueden mostrarse en público sin considerar lo que sus características significan para los otros. Ellos se atreven a sobrepasar la censura con su vestimenta o sus actitudes: por ejemplo, hay jovencitas que se apropiaron del fetiche de la Gothic Lolita vistiéndose como mucamas francesas a la moda del siglo XIX con cofia, mandil y medias de encaje en imitación de personajes consagrados por animes como Rozen maiden o Darker than light, para participar en los eventos. Lo mismo que los luchadores, samuráis, colegialas, pokemonsters o guardias imperiales.

Por eso se presenta un rompimiento que muchos participantes ratifican por unanimidad: no salen a la calle vestidos así. No viven en sus personajes ni se integran a los grupos a partir de un aspecto físico unívoco ni mediante un código uniforme que, además y por eso, sea "contracultural". “¿Para qué saldría así? No gano nada porque nadie sabe lo que quiero decir". "En mi casa ni saben que me visto así; yo creo que ni aquí porque no todos me reconocen". "Me moriría de vergüenza si supieran". "Tengo mucho miedo de que me hagan algo en la calle".

\section{Los jugadores}

"¿Es cierto que ustedes no tienen vida?", se repite la pregunta y una otaku en su presentación de la gata Felicia (del videojuego Darkstalkers) mueve dos veces la comisura izquierda de los labios y se da media vuelta golpeando sin querer al impertinente con su cola blanca.

Al mismo tiempo, una empleada de intendencia del Ceart, de largas canas, pasa junto a un grupo de videojugadores que exclaman alegremente con la broma: "Miren nomás, otro Inuyasha..." (referencia al protagonista andrógino de dicho anime, de larga cabellera blanca y orejas de gato).

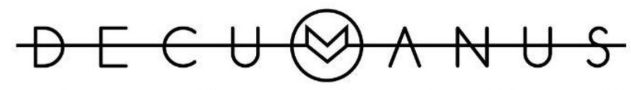

REVISTA INTERDISCIPLINARIA SOBRE ESTUDIOS URBANOS 
Los videojugadores comparten, a su propio juicio, numerosas referencias, acercamientos y gustos con los seguidores de manga/anime por el hecho de que ellos mismos lo son. Sus intereses por el videojuego trascienden este límite y los llevarán a otro campo. Es sugerente observar los movimientos agitados del jugador sobre la palanca de la máquina y su semejanza con los manoteos angustiosos que los otakus dejan escapar para hacerse notar en una de las ruidosas mesas de venta asaltadas por un público masivo.

Cuando se les pregunta, los gamers ofrecen una interpretación de primer orden, es decir, las que nacen en las opiniones propias de los informantes, sobre su relación con el manga y el anime. Es común ver a varios de edades superiores a los treinta años opinando que ellos vieron el surgimiento del movimiento, aunque es un fenómeno, el de la perspectiva propia.

A este se acude al entrevistar e interpretar a los otakus en situación, quienes no se limitan a pensarse como tales sino que intentan plasmar algunas diferencias con el "otaku original japonés", siendo estas el motivo último de la presente investigación: muchos improvisan competencias deportivas de carreras y luchas en la explanada adyacente al salón, otros se organizan en pequeños grupos y todos socializan, siempre en el espacio del ambiente fijado por los otakus participantes, que intenta parecerse cada vez a las convenciones que pueden verse en Internet.

\section{Asociación de los otakus}

Las interpretaciones de segundo grado, las que el investigador puede hacer a partir de su experiencia con los individuos con los que interactúa, vienen con las comparaciones: "Yo no soy tan otaku, pero a veces sí me siento como el de Densha Otoko". "Yo tengo mis etapas en que no salgo de mi cuarto, pero sí puedo salir y relacionarme". "Sí, la verdad es que sí me parezco a los otakus japoneses que no piensan en otra cosa que, tú sabes, eso...". Y esto conlleva la observación de sus actitudes específicas en la comunidad otaku.

Tales demostraciones de asociación se manifiestan generalmente en la actuación en la estructura de ambiente, en la posibilidad de expresión espontánea que ofrece el otaku que de pronto empieza a luchar con otro sin perder la sonrisa ni, en ocasiones, un acento de japonés chapurreado, en una escena extraída de un anime y vuelta a montar en la fila de entrada al salón de la convención o frente a un puesto de venta.

Otro ejemplo es la actitud del otaku que, al preguntársele, trata de resumir lo mejor que puede la historia de su afición, un minuto antes de reintegrarse corriendo a la fila del sushi y constituyéndose así en "modelo nativo", en este caso, un otaku japonés ideal (como el hikikomori, que vive únicamente para sus aficiones), que en realidad está respondiendo a la idea básica del otaku según la Internet.

Ahí se descubre la asociación individual a una idea (el otaku obsesionado que disfruta a cada momento del manga/anime sin tener mayor contacto con el resto del mundo) antes que una identidad grupal formada ante una línea de acción: "Pues yo empecé viendo las caricaturas del Canal 5 por-

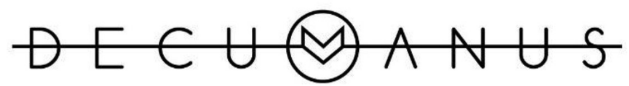

REVISTA INTERDISCIPLINARIA SOBRE ESTUDIOS URBANOS 
que yo creo que me dejaban sola mucho tiempo y no tenía otra cosa que hacer". "Mi mamá prefería ponerme Los Caballeros del Zodiaco antes que regañarme por mis travesuras y para entretenerme". "Siempre estuve solo en mi cuarto viendo mucha televisión".

Volviendo al aspecto exterior, encontrarse con los otakus congregados en la convención o incluso antes de entrar a ella puede recordar la noción general que el público tiene de los grupos de darks o góticos: los rostros muchas veces compungidos, o a veces alegres según el caso, por el personaje que representan. Los participantes aparecen velados por una respuesta constante a los otros que interpretan una participación desde la manifestación latente de su personaje, pero sin desprenderse nunca de su personalidad propia.

Lo anterior sirve como ejemplo del espectáculo de grupos de, mínimo, dos otakus que solo parecen tales por la interpretación de un personaje a causa de sus charlas cotidianas y sus movimientos mucho más naturales, como de calle.

En la interacción de la comunidad otaku, estos momentos usualmente aparecen alrededor de las mesas y los puestos de venta y también en el escenario, dando lugar a eventuales "vacíos" en los que la "actividad otaku" cesa por unos instantes $\mathrm{y}$, mientras vuelve, el fan regresa a sus quehaceres y circunstancias ajenas a su afición.

\section{Otakus fans}

Sin embargo, los momentos "huecos" de la convención, en donde no ocurre ninguna acción inmediatamente iden- tificable, se alegran cuando un evento central tiene lugar y es entonces cuando el equipo de sonido anuncia la presentación. De pronto, uno de los actores de doblaje que interpretan en español a diversos personajes como Goku (Dragon Ball Z: Mario Castañeda), Inuyasha (Inuyasha: Enzo Fortuny) o incluso Homero Simpson (Los Simpson: Humberto Vélez).

Así, entre el griterío, se percibe la unidad a brazos alzados y gargantas frenéticas por primera vez, si exceptuamos el concurso de canto, que en realidad no arrastra a la mayoría de la multitud otaku con la contundencia de las figuras arriba mencionadas. La expresividad de la asamblea da cuenta de su capacidad pulmonar gritando y ovacionando cuando, a petición general, Castañeda abre su participación adoptando la posición de ataque de Goku y grita "iiiKame-kame-ha!!!" y la voz, oh, sorpresa, le sale "igualita" a la de su personaje consagratorio; y cuando los otakus vuelven del impacto, lo que sigue es la sesión de preguntas y respuestas en que los asistentes aceptan cada palabra del invitado de honor con risas y sonrisas de veneración.

Acto seguido, hay una presentación a manera de charla del invitado de honor con los convencionistas, ya debajo de la tarima, y continúan los interrogatorios. Vuelve a entrar la prensa invitada, que antes ha tenido una sesión exclusiva con los invitados especiales, y mientras uno de estos, actor de doblaje, habla sentado a la mesa ante los micrófonos, un rosario de otakus desfila tras él: un Goku, un Super Mario, una Mai Shiranui (Samurai shodown) y otros cosplayers incomprensibles, todos sonrisas.

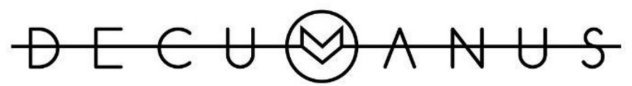

REVISTA INTERDISCIPLINARIA SOBRE ESTUDIOS URBANOS 
Paradójicamente, en estas actitudes no se aprecia tanto al otaku como al "fan", al "groupie" que va tras su estrella favorita y el código por el que se conducen, hasta por sus gritos intermitentes, es el de los seguidores de las popstars hasta que se empiezan a observar algunos gestos (el kamekameha de un Goku o el rostro desencajado de una colegiala de True tears), entre los otakus cercanos a Fortuny en la foto del recuerdo y entonces el espacio se vuelve a activar bajo el "código otaku" y el ambiente del momento vuelve a conectar con el ambiente general de la convención.

Esta teatralidad que aparece en el escenario de la convención está respondiendo así a la presentación de la imagen: un vampiro de Castlevania saluda a un pequeño en compañía de su padre quien, en cuanto le pide una foto con su hijo, permite la transformación del cosplayer en un amenazante y siseante príncipe de la noche.

\section{Las personificaciones}

Un efecto interesante de esta escenificación masiva que es evidente desde la entrada a la convención es el de los persocom, practicantes de cosplay que participan, imbuyéndole de su estilo manga/anime específico, en las "ventas de esclavos" donde cualquier asistente puede adquirir a su personaje predilecto desde la módica cifra de un peso, lo que no impide que numerosos "lotes" sean rechazados con frecuencia. El vampiro es vendido en trescientos pesos y un Inuyasha por diez. Los felices compradores (porque se les ve felices) tienen derecho a disfrutar de su compañía durante una hora y me- dia al término de la cual hay una nueva cita en el entarimado para iniciar la segunda etapa de la actividad.

Bajo la amenaza inicial de dar veinticinco vueltas a las instalaciones, que arranca carcajadas, el maestro de ceremonias invita a los persocom a colocarse tras la línea de salida para la carrera y después de dos vueltas cada uno de los esclavos sube a la tarima y grita al micrófono: "Lo que yo hago por mi amo", para así ganar su libertad.

Una lectura que puede hacerse del persocom es que es una actividad lúdica en donde el cosplayer interpreta, dramatiza, a su personaje durante el lapso fijado, pero en realidad ninguno de los dos tiene el talante para expresar sus imaginarios así, y es mejor ponerse a platicar dando la enésima vuelta por las mesas de la convención hasta que esta termina.

Cuando, en contadísimas ocasiones, otakus locales se han reunido para celebrar sus aficiones, lo han hecho en torno a la organización de pequeños eventos bajo un mismo techo: un grupo de videojugadores se ubica en el rincón destinado a las consolas y viejas "maquinitas" de Arcadia, otro sector se instala en mesas destinadas a concursos de "cartitas" de Yugi-oh! y varios más instalan mamparas o se valen de algunas paredes para exponer su fanart, como dibujos a lápiz, acuarelas o hasta óleos de sus personajes más entrañables del manga/ anime, donde se distingue una vieja escuela de universitarios que reproducen escenas y figuras de LoS Caballeros del Zodiaco, Street Fighter II, Supercampeones, Dragon Ball Z, Robotech o Mazinger $Z$, y otakus de más reciente cuño que han variado sus

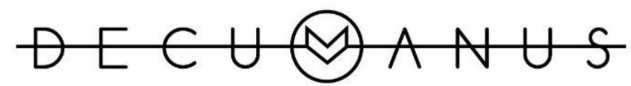

REVISTA INTERDISCIPLINARIA SOBRE ESTUDIOS URBANOS 
gustos gracias a una oferta masificada y multiplicada, estampando en el dibujo motivos de Naruto, Digimon, Escaflowne, Bleach o Cowboy Bebop, una variedad compartida por una importante cantidad de asistentes que los hace trascender los simples géneros para obedecer centralmente, como se verá, a la filiación personal a cada faceta de la fenomenología otaku.

\section{La apariencia del otaku en sus espacios}

Los otakus locales dejaron de ser localizables en Mexicali por parte de cualquier observador externo como "contracultura" en la medida en que se les consideró (y ellos se asumieron como) dependientes de los productos de la industria cultural. Así resultó más fácil alejarlos de la parcela compartida por las tipologías (antisociales) "cholo" o "anarcopunk" para identificárseles como asociados al gusto y apariencias del geek en oposición al talante (asocial) del freak refugiado en la tradición endogámica que se unifica por su rechazo pasivo al statu quo de la clase media a la que en abrumadora mayoría pertenecen.

Esta noción hace referencia no tanto al origen histórico como a la conformación típica del grupo que se define por sus funciones, por lo que aspira a ser y por las asociaciones que sus integrantes hacen de sus vidas (en un ejercicio constante de personalización y recuerdo de los argumentos del manga/anime) con los contenidos a los que su afición les expone. Para quien pueda observarlos, este gusto es generador del grueso de los com- portamientos externa e internamente vinculados al ser otaku.

Tal consideración sobre el origen y características del otaku mexicalense es lo que puede concluirse, en parte, de las respuestas constantes de los seguidores de manga y anime que dudan de las posibilidades de su grupo de erigirse en instrumento contracultural para incidir en la sociedad, pues a primera vista se observaría que el principal de los mayores desintereses de los otakus sesionando en cualquier convención de fanáticos es la política: "A mí no me interesa nada de eso". "Todo es la misma porquería". "Los políticos son reptiles gigantescos ocultos tras un traje y con apariencia humana". O "yo nunca voy a votar". Son expresiones comunes en aquellos a quienes se les inquiere sobre el tema, y esa misma actitud es compartida en términos generales con las temáticas que impliquen un acercamiento con los procesos ideológico-filosóficos que configuran la mentalidad dominante sobre valores trascendentales y corrección política, lo que, a decir de los otakus más reflexivos o con quienes se puede llegar más lejos en una charla off-topic, obedecería a un aburrimiento general que testimonia el rechazo a las condiciones exteriores que les habrían predispuesto a su refugio en la alteridad otaku.

Algo notable de las relaciones entre los grupos de fanáticos es su condición de agrupaciones independientes y dispersas que operan en la forma de sesiones de apreciación de anime, mismas de las que no saldrá ningún resultado ni expectativa que no sea acaso el compromiso de una nueva cita.

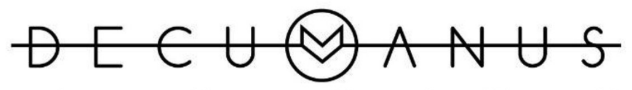

REVISTA INTERDISCIPLINARIA SOBRE ESTUDIOS URBANOS 
Así, las convenciones de manga y anime no son un espacio de encuentro orientado a la presentación en sociedad de un grupo bien estructurado por un solo interés; más bien se puede entender, por palabras de un grupo de seguidores de las películas dirigidas por Hayao Miyazaki, como el resultado final de una serie de encuentros y operaciones logísticas, claro, pero esencialmente de un conjunto de pequeñas necesidades manifiestas por cada grupo que desea incluir su nicho. A partir del desarrollo de estos bajo la dinámica de la convención, es posible entrar en contacto con otros fanáticos de intereses comunes, pero más especializados, que incluso poseen la característica de ser excluyentes ante otros nichos.

Cuando asistí a las convenciones pude tener la certeza de que todo contacto personal con cualquier participante no pasaría del intercambio de saludos elementales (tampoco es muy válida una pregunta por su anime favorito si se desea empezar a profundizar con él/ella desde el primer momento) y hay fanáticos que opinan que esto se debe al conocimiento de la gran mayoría de los participantes con que los convencionistas cuentan luego de haber pasado varios de estos eventos.

En ellos pueden ponerse en contacto con los mismos grupos de otakus: "No es que sean groseros, es que no hay nada de qué hablar". Lo que no querrá decir que se debe atribuir una actitud reservada a sus malos modales, que son un asunto personal, sino que, como el investigador puede inferir de diversos testimonios, los convencionistas acceden a los even- tos con un solo objetivo, haciendo de estos un espacio sin mayor atractivo para el público masivo local que no comparta la misma afición y que se sentiría ajeno dentro de un galerón caluroso anegado de aisladas peroratas en "japañol":

Muchos fanáticos hablan en ocasiones utilizando cortesías en japonés intercaladas con su idioma materno. No son de extrañarse las expresiones sacadas del anime o de algún videojuego, como tampoco intercambiarse saludos respetuosos (ogenki desu ka?; totemo genki desu, arigato; genki desu, konbanwa. ¿Cómo estás?; Muy bien, gracias; Bueno, buenas noches).

Una estudiante con el uniforme de colegio japonés, un guerrero-dios de la muerte (shinigami), un peleador salido de un videojuego como Fatal Fury, Street Fighter Alpha, Darkstalkers, Mortal Kombat Ultimate, Samurai Shodown, incluso personajes de Kill Bill, un chico con el mismo peinado del protagonista rubio (aunque perfectamente japonés) de Death Note, dos o tres (o 12 o 13) Caballeros del Zodiaco, un pelotón de Super Saiyayines expulsados de Dragon Ball $Z$.

También hay un equipo más o menos completo de Supercampeones (un atuendo mucho más fácil de improvisar), un fontanero de bigote y gorra roja o verde, pequeñas Sailor Moon, Júpiter o Saturno; camisetas, muchas camisetas, aunque se observa un chispazo de la moda geek de adornarlas con leyendas sarcásticas donde la haya o marcas de productos retro para sustituírseles, prendas que se sospecharían sido importadas desde Tokio o San Diego, sin olvidar que el toque local de la convención entre otros,

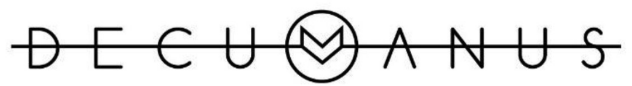

REVISTA INTERDISCIPLINARIA SOBRE ESTUDIOS URBANOS
Núm. 2. Vol. 2. Octubre 2016-Octubre 2017. Instituto de Arquitectura, Diseño y Arte.

Universidad Autónoma de Ciudad Juárez. ISSN: 2448-900X 
viene dado por el "comic americano" y la formidable cantidad de referencias a los comics de las editoriales Marvel y DC Comics, pero también al canal de paga Cartoon Network y sus productos de animación fallidamente emparentada, según los citados seguidores de Miyazaki, con las cuadradas y casi inmóviles caricatures coreanas de la presente década.

Otro nicho especial lo ocupa el merchandising periférico que puede utilizarse como lenguaje del fanatismo (fandom) para ubicar las tendencias de los usuarios y así clasificar de inmediato según el orden al que pertenezca cada categoría argumentística que no establece una jerarquía, que es innecesaria.

Más bien, se trata de un campo que puede favorecer interacciones personales que no toman como principal prioridad el hecho de ser otaku, pues aquí lo que importa es la comunicación de intereses y deseos específicos (conocer un anime que solo otros dos asistentes a la convención adoran) que echa por tierra la pretensión de un campo unificado, como muchos de los mismos fanáticos perciben que es el mundo del otaku japonés, por el hecho de que las noticias que les llegan siempre hablan del mismo comportamiento reclusivo.

Una joven artesana (que nunca se había interesado ni conocía el manga/ anime a profundidad) instaló un puesto de venta de libretas encuadernadas por ella misma con papel reciclado hecho cartoncillo con hojas secas como ornato. El primer día no vendió ninguna. Sin embargo, estando presente en el evento desde la mañana hasta la última hora de la tarde, le sirvió de mucho la amplia observación que el ocio le permitió: Mientras los otakus se acercaban a tocar sus productos y a veces mostrar gestos de admiración para luego retirarse sin comprar nada, pudo leer la multitud de códigos coloridos impresos por todo el recinto hasta en la ropa y pertenencias de los participantes, y las reglas de la atracción que de alguna forma mutan y se reinterpretan, con inexplicable rapidez para quien no pertenece al campo, para fijar los encantos que capturan a este estamento de consumidores. Por eso, no se desanimó y decidió volver al segundo día de actividades: la noche anterior se conectó a Internet y se dejó llevar por el arcoíris de personajes y sentimientos ofrecidos por el fandom que tiene en el ciberespacio otaku su verdadera territorialidad y pudo encontrar, no solo respuestas a muchas de las sorpresas codificadas que circulaban por la galería principal del evento, sino además la clave de la carencia central de su producto, tal y como el exigente público lo desdeñó.

Al día siguiente por la mañana se presentó con sus libretas adornadas con estampados de Doraemon, Hello Kitty!, Strawberry Shortcake, Pucca, Ranma 1/2, Digimon o incluso Astroboy. A mediodía ya no le quedaba ni una sola. El precio, veinticinco pesos, no había sido castigado y nuestra chica no había echado a andar ninguna oferta: simplemente, tales artículos dignos de colección eran mucho más atractivos de lo que el precio anunciaba: eran coleccionables, y la vendedora ni sabía de lo que se estaba deshaciendo.

En los grupos otaku que se reúnen durante las convenciones (asumamos que esta es la única clase de eventos

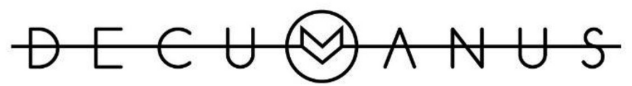

REVISTA INTERDISCIPLINARIA SOBRE ESTUDIOS URBANOS 
en los que el observador podría hablar de ellos desde una concepción parecida a un "campo unificado") se puede observar a cada una de las incontables células que antes hemos clasificado en forma muy sucinta como una isla que se integra dentro de la categoría "otaku" solo como una consecuencia en general inevitable de la relación de los aficionados con algunos de los múltiples productos de esta industria.

Las primeras relaciones o tan siquiera acercamientos con los otakus señalan la permanencia de una identidad global que en realidad no es sostenida, contrario a lo que pudiera pensarse de entrada, por un discurso en articulación continua.

Más bien lo que tenemos aquí es una colección de significados, según el gusto, que responden a intereses particulares, esto es, identidades intercambiables en el juego personal, como en el cosplay, que son, en instancia última, las que permitirán que pensemos en una identificación plena con la noción de un "fanático" de la animación japonesa.

El otaku local, a decir, además de su lenguaje cotidiano, no está inventando un discurso, sino que ha traído, y está adaptando, una discursividad que debe ajustarse al lenguaje diario con el que pueden comunicarse y al mismo tiempo crear los foros virtuales donde todo es lengua escrita que tienen a su disposición para llevar a cabo su posicionamiento ante la sociedad.

\section{El otaku en la dinámica de los foros web}

Siendo Internet el principal medio por el que los otakus adquieren informa- ción, no sólo sobre su condición, sino esencialmente sobre novedades para la obtención y transmisión de manga/ anime, es necesario un acercamiento. Los consumidores se conectan ávidamente a Internet cada vez que pueden a través de los cibercafés, pero con base en la experiencia de los informantes, por lo general de clase media, cuentan con conexión de banda ancha en casa.

El uso del foro donde pueden abrir conversaciones sobre sus temas favoritos, está ampliamente divulgado en Mexicali gracias a una web en particular: animemexicali.net; página oficial en Internet de la organización del mismo nombre, publicita las actividades de esta para organizar y difundir las actividades de las convenciones. Los participantes en su foro, previo registro gratuito, pueden acceder a los diferentes "hilos" o conversaciones en torno a diversas temáticas: series de anime y manga, música pop japonesa, mangakas (dibujantes) favoritos, televisión, cosplay, fan art, gamers y propuestas de hilos fuera de categoría.

Con tan sólo unas pocas lecturas iniciales, el visitante puede percatarse de un posicionamiento formal: "Los otakus somos buenos". A lo largo de diversas charlas es notoria la repetición de declaraciones sobre la "simpleza" de la vida otaku y lo agradable que es estar todo un día o un fin de semana completos disfrutando del manga/anime. El tono y sentido de sus expresiones se refiere constantemente a una voluntad de elección. Acaso sin saberlo, están rompiendo con el estereotipo del "otaku original" que no sale de su cuarto porque no le queda otra opción.

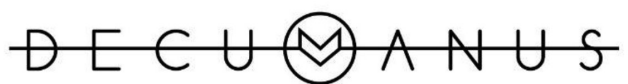

REVISTA INTERDISCIPLINARIA SOBRE ESTUDIOS URBANOS 
La fantasía interviene a cada momento, ahora enmarcada en su experiencia otaku y cómo se desarrollan sus vivencias. Ahora, lo importante es el contacto de las fantasías gracias a la exposición libre de la personalidad. Bastante elocuente es un hilo llamado “en qué anime te gustaría vivir?", que intenta encontrar los motivos de la compenetración del otaku en sus argumentos predilectos, a través de un ejercicio tan simple como la extrapolación de elementos cotidianos.

Hay además un espacio especial para preguntarse entre todos dónde compran su manga. $Y$ hay una constante casi unánime: la tienda Mundo Vid, en la Plaza La Cachanilla en Mexicali, “¿en dónde más?", inquiere uno de los foristas. Mientras, otros más recuerdan que muchos de los consumidores locales acuden a comprar a la tienda Shojo beat, en Calexico. Otra tienda es Librolandia, en el centro de la ciudad, plena de manga hentai: de repente, ante la oscuridad de la referencia, la conversación se pierde por completo en señas sobre su ubicación exacta y el hilo se puede dar por terminado, como muchos otros, que citan sobre citas sobre citas, concentrándose en temas que nada tienen que ver con el original.

El interés por mostrarse arroja la lectura de la presentación de sí mismos desde sus objetos. Las personas que son aparecen representadas por la configuración de una personalidad según el gusto. El gamer se presenta por su interés en los videojuegos de mediados de los ochenta o por su gusto por comprar o informarse de las consolas más recientes como el Playstation 3 o el Nintendo Wii.
En lo referente a la lista de hilos dedicados "a temas que no tienen que ver con nuestro rollo", hay preguntas tan simples como "¿cuál es tu pasatiempo favorito?", hechos para quienes deseen hablar de cosas fuera de categoría, aunque inevitablemente, los comentarios siempre van a parar al tema principal.

Por lo regular, el entretenimiento comunitario que afirman encontrar gira alrededor del videojuego y del visionado de anime. Muchos pasan gran cantidad de tiempo "bajando" mangas digitalizados de Internet. El entretenimiento sedentario ni siquiera se cuestiona porque no hay salidas y cualquier comentario sobre ello acercaría al impertinente a los sermones de algunas mamás que están preocupadas porque su "niño(a)" no sale del cuarto y solo se "envicia" con esos "monos chinos". La conexión a Internet es permanente. De banda ancha.

Algunos aprovechan el espacio y el pseudónimo (nick/avatar) para confesar que han dejado la computadora encendida, "bajando", durante una semana entera o más. La asignación de una identidad se implementa en estos espacios a través de las "firmas" personales que el participante elige para adornar y validar cada uno de sus mensajes.

Incluso pueden verse personajes de Los Simpson o de la lucha libre estadounidense al lado de cosplayers o distintos animes: lo que importa aquí es el ambiente estructurado en torno al manga/anime que rezuma incluso en la forma de escribir. Una estructura que es deudora del mismo orden colorido facilitado por la colección. Muchos asistentes al foro platican sobre las

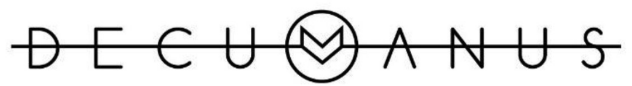

REVISTA INTERDISCIPLINARIA SOBRE ESTUDIOS URBANOS 
distintas formas de acomodar sus espacios dándole prioridad a la idea de que parezcan los de un otaku. Gustan de hacer saber que ahí es donde pasan más tiempo, además de la escuela.

Algunos todavía recuerdan las fotos de la habitación de Tsutomu Miyazaki, violador y asesino de niñas que habría sido inspirado por el hentai y que pasaría a la historia, en 1989, como el ejemplo más elocuente del otaku criminal por el que se estigmatizaría a los seguidores del manga/anime como seres ermitaños y depravados: "Tenía las paredes llenas de mangas... qué chilo", "Sí, pero yo no haría lo que él hizo...", "No, pero su cuarto sí que se parecía las tiendas de manga de allá..."

Cuando se abre un hilo dedicado a que los foristas contesten un "chismógrafo" que incluye preguntas relativas a sus gustos y vivencias personales, la mayoría de los que aseguran con gusto no haber practicado nunca ningún deporte es abrumadora.

En contraposición a la imagen ideal, "teórica", del otaku, con frecuencia pueden encontrarse hasta dos hilos, cerrados o abiertos, dedicados a las experiencias amorosas de los participantes. Si bien puede comprobarse este componente de su personalidad como punto débil en función de su a veces muy escasa socialización, cabe destacarse el interés general por relacionarse en diversos espacios y con más gente, aunque también el miedo por encontrarse con personas que no entiendan sus gustos.

En 2007, un grupo de otakus locales decidió abrir un local por la avenida Lerdo en Mexicali que se denominó Otaku house. La idea era crear un café centrado en el concepto de los mai- den cafe de Tokio, en donde jovencitas cosplayers atenderían al cliente ("¿En qué te puedo servir, mi amo?") con la total sumisión de un personaje kawaii, caricaturizando al servicio y al ambiente completo del lugar.

Lo anterior a la manera del colorido propio del cosplay, en referencia a la costumbre de sus creadores, como del resto de los otakus cercanos al proyecto a través del foro, por entrar caracterizados al centro comercial Plaza La Cachanilla. Los guardias de seguridad los desalojaban bajo las denuncias de indumentarias "escandalosas", pero sobre todo por la "irregularidad" que representaba un grupo de individuos no identificables bajo el maquillaje y los accesorios propios de la dinámica cosplay.

Fue entonces cuando decidieron retirarse a su propio espacio en las cercanías, en la antes citada avenida. Sin embargo, pronto se presentó un problema que no era menor: se invitaba a las chicas participantes en el foro a que aplicaran al puesto de meseras del lugar vistiendo a la manera de las mucamas francesas tan populares en diversas series de manga/anime romántico, pero también hentai, aunque muchas se negaban ("Ni pensarlo", "La neta sí soy muy tímida y no podría. Además, mis papás no me dejan").

En el centro de todo, como se comprobaba avanzando en el hilo, ya cerrado, el temor al rechazo a lo diferente y a la constante erotización, por la exotización occidental de diversos elementos de la cultura japonesa en el manga/anime.

Por ejemplo: “Ay, no, es que muchos ni saben ni qué onda y no sabrían respetar, y tengo miedo de que

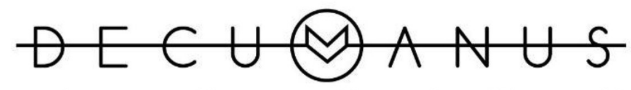

REVISTA INTERDISCIPLINARIA SOBRE ESTUDIOS URBANOS 
me digan cosas o que me hagan algo", o también, un comentario muy revelador: "Los que vayan ni van a entender por qué lo haríamos, creerían que es como un prostíbulo o a lo mejor alguna cosa parecida y no es eso y no es tan simple porque se trata de nuestros gustos y ahí sí ya cambia".

El ambiente era generado, como en el caso de la convención, por una microestructura que estaba destinada a repetir elementos del manga/anime o simplemente de contenido japonés vía la experiencia vicaria, de nuevo, dependiendo en su mayoría de los sitios de Internet.

\section{Conclusión}

La construcción sociocultural del fanático depende de su inmersión constante en el mundo que se ha construido y en el que se adiestra para salir a la calle y relacionarse desde su punto de vista sobre las condiciones del mundo que las demás personas han acordado como "real". Partí desde el imaginario por considerar qué argumentos, estética y antecedentes culturales del manga/anime inciden en aquellos elementos de la imaginación que comprometen la creatividad personal del otaku. Vivir en una dinámica psíquica en la que constantemente se regresa al manga/anime es la inspiración para crear una dimensión propia que es mucho más complaciente que el espacio social cotidiano.

De ahí la afiliación del otaku a un grupo de fans como él. Sin embargo, este grupo no tiene la vocación de presentar su identidad frente a una realidad susceptible a ser cambiada. Su identidad no se proyecta hacia el exterior como demanda de una transformación con la que ellos hagan una aportación sustancial. Simplemente, sus redes sociales operan para organizar y distribuir información y productos manga/anime, difíciles de conseguir por iniciativa individual.

Así, los otakus permanecen en el espacio imaginario de su afición, renunciando a otras actividades que puedan distraerlos, aunque sin aislarse tanto como para caer en la identidad marginal. En sus relaciones sociales se mantienen operativos en sociedad, estudian, tienen empleo; muchos salen de viaje, tienen pareja y conviven con sus padres.

La Internet es una herramienta insustituible para acercarse a la dimensión otaku, a su estética, referentes y gustos. Es el espacio inicial para conocer al consumidor de manga/anime y para adentrarse en la tipología a la que puede asociarse: la del fan japonés, por contar con una vida similar a la suya como otaku (a descubrir para sí e identificarse con el término mismo) agregando el enorme atractivo de vivir en Japón y ser parte integrante de un estilo de vida, incluso reflejado en el manga/ anime, al que aspira pertenecer.

Las convenciones son intentos por reproducir esta sociabilidad otaku idealizada. De ahí que los otakus participen en sus distintas actividades como si se tratara de una vivencia puesta en escena que repite los ambientes de la actividad otaku en Tokio, tal como la conocen a través de las imágenes y relatos que circulan en el ciberespacio.

Alimentar la imaginación con un sistema de narraciones e imágenes que suman legión por la fuerza de la industria, es acceder a diferentes for-

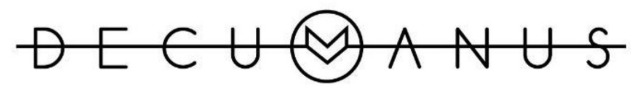

REVISTA INTERDISCIPLINARIA SOBRE ESTUDIOS URBANOS 
mas de enfrentarse a uno mismo y conocer los mecanismos que lo impelen a la acción. El manga/anime como fuente de creatividad se ofrece variado y divertido, amigable y emocionante para moldearlo según los sentimientos particulares de sus usuarios.

La impronta sociocultural del manga/anime puede comprobarse en espacios como las convenciones o los foros electrónicos, lo mismo que en la producción artística de los otakus. Sus trabajos y manifestaciones manifiestan su existencia, demandando la atención de los miembros de su entorno. Su aparente anonimato es una invitación a sentir y vivir, con un estilo particular delimitado por el espacio geográfico, el acercamiento a otra cultura, la japonesa, con sus propias emociones, visiones, estética e historias gracias a productos industriales masivos. Los productos que permiten gozar de un momento de alegría y tranquilidad gracias a su integración en el imaginario individual merecen ser considerados como aportaciones a la humanidad que amenaza con perderse bajo los embates de la codicia y el dolor tecnificados. Ser otaku es estar consciente de la necesidad de un espacio íntimo para el crecimiento personal, para la supervivencia de una cultura particular que merece participar de la pluralidad cultural reconocida por las sociedades actuales. Ser otaku es seguir siendo humano.

\section{Referencias}

Ardevol et al., "Etnografía virtualizada: La observación participante y la entrevista semiestructurada en línea", en Atenea digital, Barcelona, 2003.
Grassmuck, Volker, “'I'm alone, but not lonely'. Japanese otaku-kids colonize the realm of information and media. A tale of sex and crime from a faraway place", en http://www.cjas.org/ leng/ otaku-e.htm, 1990.

Greenfeld, Karl Taro, Speed tribes. Harper Collins, Nueva York, 1995.

Kinsella, Sharon, "Amateur manga subculture and the otaku panic", en Journal of Japanese studies, 1998.

Pinillos, Isabel, "El coleccionista y su tesoro: La colección", ponencia para el XX Congreso Anual de AEDEM, Palma de Mallorca, 2006.

Piscitelli, Alejandro, Ciberculturas. En la era de las máquinas inteligentes. Paidós, Barcelona, 1995.

Roszak, Theodore, El nacimiento de una contracultura: reflexiones sobre la sociedad tecnológica y su oposición juvenil. Kairós, Barcelona, 1973.

Schodt, Frederik, Manga!, Manga!, the world of Japanese comics. Kodansha, Tokyo, 1986.

Tobin, Joseph J. (ed.) Re-made in Japan: everyday life and consumer taste in a changing society. Yale University Press, New Haven, 1992.

Vásquez Rocca, Adolfo, "Coleccionismo y genealogía de la intimidad", en Almiar, Madrid, 2006.

Whipple, Charles, "The silencing of lambs", recuperado el 19 de marzo de 2007 en: http://www.archive.org/www.charlest. whipple.net/miyazaki.

White, Merry, The material child, The free Press, Nueva York, 1993.

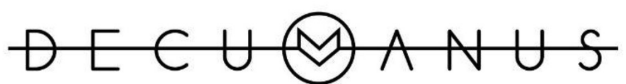

REVISTA INTERDISCIPLINARIA SOBRE ESTUDIOS URBANOS
Núm. 2. Vol. 2. Octubre 2016-Octubre 2017. Instituto de Arquitectura, Diseño y Arte. Universidad Autónoma de Ciudad Juárez. ISSN: 2448-900X 